\title{
Comparison of Thoracolumbar Interfascial Plane Block with the Application of Local Anesthesia in the Management of Postoperative Pain in Patients with Lumbar Disc Surgery
}

\author{
Mustafa BICAK ${ }^{1}$, Ulas AKTAS ${ }^{2}$, Fikret SALIK ${ }^{1}$, Hakan AKELMA ${ }^{1}$, Esra AKTIZ BICAK ${ }^{1}$, Sedat KAYA ${ }^{1}$ \\ ${ }^{1}$ Health Sciences University, Gazi Yasargil Training and Research Hospital, Department of Anesthesiology and Reanimation, Diyarbakir, Turkey \\ ${ }^{2}$ Health Sciences University, Gazi Yasargil Training and Research Hospital, Department of Neurosurgery, Diyarbakir, Turkey
}

Corresponding author: Mustafa BICAK drmustafabicak@gmail.com

\section{ABSTRACT}

AIM: To compare the effect of ultrasound-guided modified thoracolumbar interfascial plane (TLIP) block versus local anesthetic infiltration on the wound site for post-operative analgesia in patients undergoing lumbar disc surgery with spinal anesthesia.

MATERIAL and METHODS: This prospective and observationally planned study included 42 patients from the ages of 18 to 75 years, American Society of Anesthesiologists classes I-III, who underwent lumbar disc surgery. In Group L, bupivacaine infiltration was performed on the surgical incision line. In Group T, TLIP block was performed with ultrasound. In the postoperative period, visual analogue scale (VAS) values were also investigated and recorded on the $10^{\text {th }}$ day after discharge. Nausea, vomiting, and sedation score values and analgesic doses used by all patients in the postoperative period were recorded.

RESULTS: During any of the postoperative follow-up hours, the VAS score was $\leq 3$ (mild pain), and those who did not need tramadol were $80.9 \%(n=17)$ in Group T and $71.4 \%(n=15)$ in Group L. VAS scores at the $1^{\text {st }}, 4^{\text {th }}$, and $8^{\text {th }}$ hours were statistically lower in Group $L$ than those in Group T ( $p$ values: 0.011, 0.028, and 0.029). The average amounts of tramadol consumption per patient were determined as $19.04 \mathrm{mg} \pm 40.23$ in Group T and $27.38 \pm 44.65 \mathrm{mg}$ in Group L in the first 24 hours postoperatively. There was no statistically significant difference between groups $(p=0.519)$.

CONCLUSION: In this study, it was determined that the modified TLIP block application performed for the purpose of post-operative analgesia in lumbar disc surgery was not superior to local anesthetic infiltration in terms of postoperative opioid consumption and VAS scores.

KEYWORDS: Thoracolumbar interfascial plane block, Local anesthesia, Postoperative pain, Lomber disc surgery

\section{INTRODUCTION}

$\mathrm{P}$ ostoperative pain and its management after lumbar spinal surgery are still an important problem for modern anesthetists. Severe or moderate postoperative pain lasting for 3-4 days is generally observed in patients. The observed acute pain starts with a surgical incision and, if not managed properly, may result in chronic pain (13). In patients with effective pain control, it has been shown that there is a decrease in complications related to immobilization such as deep vein thrombosis, lower mortality and morbidity, and an increase in patient satisfaction.

Among the multimodal analgesia techniques that can be used are opioid agents, non-opioid agents, neuroaxial blocks, local anesthetic agent infiltration to the wound, and other non-pharmacological methods. Since patients have moderate or severe pain, opioid agents are often utilized as the first choice. Opioids used in the postoperative period have caused anesthetists to turn to alternative methods in recent
Mustafa BICAK (10) : 0000-0002-7658-5143

Ulas AKTAS (D) : 0000-0003-0362-4751

Fikret SALIK (1): 0000-0002-7715-3545
Hakan AKELMA (10: :0000-0002-0387-8738

Esra AKTIZ BICAK (D) : 0000-0003-1976-1179

Sedat KAYA (1) : 0000-0002-9894-9091 
years due to wide side effect profiles such as respiratory depression, impaired cognitive function, delay in wound healing, development of tolerance, cardiovascular stress, and urinary and gastrointestinal dysfunction (17).

Applying a local anesthetic agent to the wound site, which was first described by Mullen and Cook in 1979, later showed to be an effective method of analgesia in the postoperative period in many studies and to reduce opioid consumption $(11,12,14)$. However, in recent years, the new uses of ultrasonography (USG) in regional anesthesia and new technical definitions have emerged. One of these techniques is a new block technique, TLIP block, studied by Hand and friends on volunteers in 2015, being placed in the literature by them (7). This block technique is based on the principle of giving local anesthetic agent between the multifidus and longissimus muscles at the level of the 3rd lumbar vertebra with a 30-degree angle through the skin from lateral to medial and blocking the dorsal branches of the thoracolumbar nerves. The other one was defined by Ahiskalioglu et al. on 2017 as a modification of this technique (1). In the modified TLIP technique, the needle is directed from medial to lateral at a 15-degree angle from the skin, and the local anesthetic agent is delivered between the longissimus and iliocostalis muscles. Thanks to the modified technique, it has been shown that the risk of neuraxial injection is reduced since the orientation is made from medial to lateral, and the block success chance is increased because ultrasonographic separation of longissimus and iliocostalis muscles is easier (1).

This study, which was designed prospectively and observationally, aims to compare the application of TLIP block with the preemptive application of local anesthetic agent on the wound site in the management of postoperative pain in patients who underwent spinal surgery for lumbar disc herniation.

\section{MATERIAL and METHODS}

This prospective and observationally planned study was performed with 46 patients of American Society of Anesthesiologists (ASA) classes I-III at the Diyarbakır Gazi Yasargil Training and Research Hospital after the approval of the local ethics committee (No. 407-dated 20.12.2019). Written informed consents were obtained from the patients, aging 18-75 years old. The study was carried out in accordance with the Helsinki declaration article II.

Patients under the age of 18 or over 75 years, patients with ASA > III, patients with a history of allergy to the drugs to be used, patients with morbid obesity (BMI > 35), patients with chronic pain and treatment history, patients with substance abuse history, emergency cases, and those with infection in the procedure site were excluded from the study.

The patients were evaluated in an outpatient clinic by an experienced anesthesiologist before surgery. They were given detailed information about the surgical procedure, anesthesia technique, and procedures that can be applied for pain management control in the postoperative period. They were told about the Visual Analogue Scale (VAS) used for pain assessment. Patients were asked to express pain intensity from 0 to 10 , with 0 for no pain in the postoperative period and 10 for the most severe pain. All patients were given the phone number of a researcher they could reach in case of any problem that might occur in the perioperative period.

Before surgery, patients were provided with intravenous access from the antecubital area with a standard 20-gauge cannula. In the waiting room, patients were given $2 \mathrm{mg}$ of midazolam intravenously. Standard electrocardiography, peripheral oxygen saturation, and noninvasive blood pressure monitoring were performed in the operating room (Dräger Infinity delta $\mathrm{XL}$ ).

The patient was placed on a sitting position. Spinal anesthesia was inducted through the $3^{\text {rd }}$ and $4^{\text {th }}$ lumbar intervertebral space under sterile conditions with a 26-G Quincke needle (EGEMEN-Turkey). After spinal anesthesia, patients were placed in supine position. Patients who had spinal anesthesia but failed spinal block were excluded, and the same number of new patients was added to the study. After an adequate block level was observed, patients were placed in prone position. Two patients were excluded from the study because they had $\mathrm{BMI}>35$, and the study was continued with 44 patients. In 21 patients, bilateral application of $50 \mathrm{mg}$ of bupivacaine to the surgical incision line (a total of $100 \mathrm{mg}$ infiltration) was done preemptively, and this was recorded as Group $L$ (local). The remaining 23 patients were considered as Group T (TLIP block). Two patients were excluded from Group $T$ because of coagulopathy, and Group $\mathrm{T}$ was continued with 21 patients, too (Figure 1). While the patients were in prone position, the transverse processes of the $3^{\text {rd }}$ lumbar vertebra were observed with the linear USG probe (Mindray DP-50) at sterile conditions. The longissimus and iliocostalis muscles were determined from the paraspinous muscle groups. Between these two muscles, $20 \mathrm{ml}$ of $2.5 \mathrm{mg} / \mathrm{ml}(0.25 \%)$ bupivacaine was given using a 100-mm block needle (Braun peripheral nevre block needle Stimpulex, 22 gauge) at a 15-degree angle (Figures 2, 3). The procedure was also performed on the other side, and in Group T, the procedure was completed by injecting $40 \mathrm{ml}$ of $0.25 \%$ bupivacaine (100 $\mathrm{mg}$ in total). Patients with a $20 \%$ increase in mean arterial blood pressure compared to basal value during surgery were administered $1 \mathrm{mcg} / \mathrm{kg}$ intravenous fentanyl and recorded.

In the postoperative period, 30-min and 1-, 2-, 4-, 8-, 16-, $24-, 48-$, and $72-$ hour VAS values were obtained. On the $10^{\text {th }}$ day after discharge, outpatient control was recommended, and the VAS values of the patients were questioned and recorded under the control of the outpatient clinic. Also, nausea, vomiting, and sedation score values of the patients were recorded.

All patients received $1 \mathrm{~g}$ of paracetamol intravenously, with 8-hour intervals in the postoperative period. Intravenous 1 $\mathrm{mg} / \mathrm{kg}$ contramal was administered to patients with a VAS value $>4$ and recorded. If the patient's pain scores did not decrease $(<4)$ within 30 min despite contramal administration, intravenous contramal repetition at $1 \mathrm{mg} / \mathrm{kg}$ dose was planned. Fentanyl was administered intravenously at $1 \mathrm{mcg} /$ $\mathrm{kg}$ and recorded as a rescue analgesic in patients whose pain scores did not decrease $(<4)$ despite the second dose of contramal administration. 
In the postoperative period, nausea and vomiting were evaluated with a 3 -point scale $(0=$ none, $1=$ mild, and 2 $=$ severe). Intravenous ondansetron at $0.15 \mathrm{mg} / \mathrm{kg}$ was

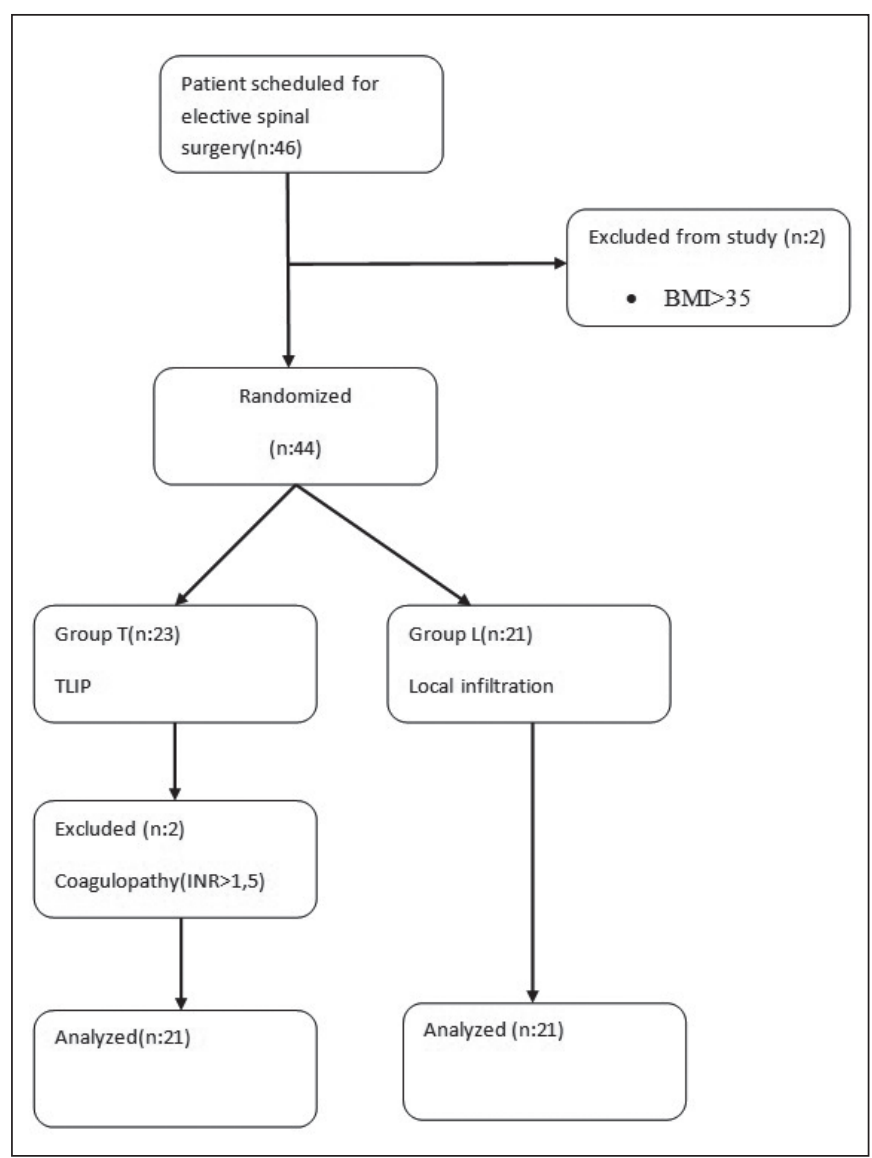

Figure 1: Flow diagram.

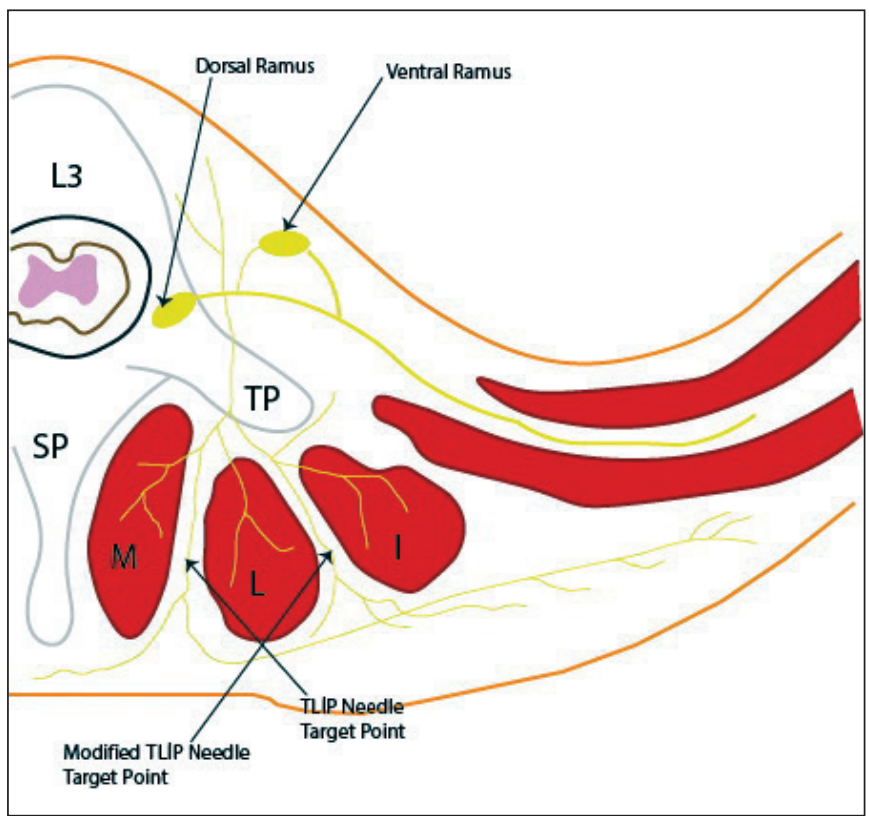

Figure 2: Thoracolumbar interfascial plane block anatomy. administered to patients who had nausea or vomiting score of 2 or could not tolerate nausea. In the postoperative period, sedation score was evaluated with a 3-point scale at 1, 2, 4, 8, 12,16 , and 24 hours (awake $=0$, sleepy $=1$, and deep sleepy $=2$ ) and recorded.

\section{Statistical Analysis}

In calculating the sample size, G*Power version 3.1.9.4 (Universität Kiel, Germany) was used, and the minimum total number of patients to be included in the study was calculated as 42 .

SPSS 16.0 for Windows (SPSS Inc., Chicago, IL, USA) was used for statistical analysis. Statistical data were expressed as mean and standard deviation (SD), while categorical data were expressed as frequency and percentage. Comparison of categorical data in the groups was done with chi-square and Fisher's exact tests. The results were given in percentages. The Kolmogorov-Smirnov test was used to determine if the numerical data fit the normality distribution. Continuous variables were expressed as mean $\pm S D$ or median $\left(25^{\text {th }}-75^{\text {th }}\right.$ percentiles). The groups were compared using the $t$ test for independent variables. The Mann-Whitney $U$ test was used for the non-normally distributed and categorical data. In all comparisons, $\mathrm{p}<0.05$ was considered significant.

\section{RESULTS}

Throughout the study, 46 patients were followed. Two patients were excluded from the study because of BMI $>35$, and then, the patients were divided into two groups as Group $T(n=23)$ and group $L(n=21)$. Two patients in Group T were excluded due to coagulopathy, and a total of 42 patients

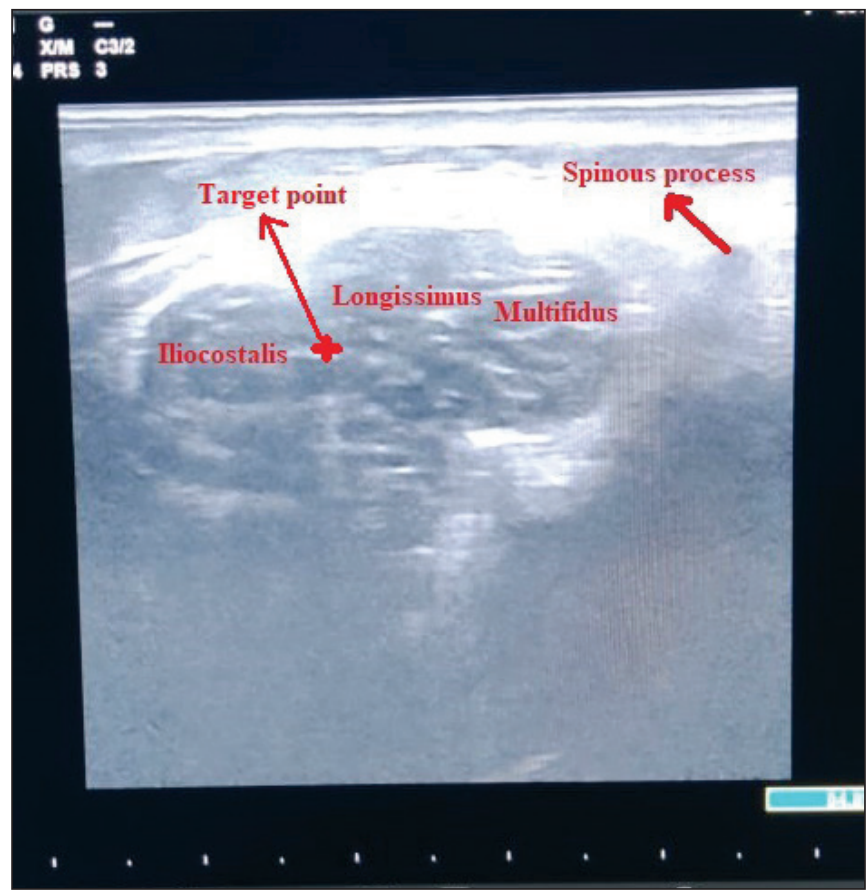

Figure 3: Thoracolumbar interfacial plane block ultrasound view and target injection site. 
completed the study (Figure 1: Flow diagram). There was no statistically significant difference between the groups in terms of demographic data (Table I). There was a statistically significant difference in terms of surgical time.

At any of the postoperative follow-up hours, the VAS score was 3 (mild pain), and those who did not need tramadol were $80.9 \%(n=17)$ in Group T and $71.4 \%(n=15)$ in Group L. The proportions of patients with a VAS score of 4-6 (moderate pain) were 19\% $(n=4)$ in Group T and $28.5 \%(n=6)$ in Group L. No patients with a VAS score of 7-10 (severe pain) were found in all groups. There was no statistically significant difference between the groups (Table II).

Table I: Demographic Data of Patients and Surgery Time (Mean $\pm(\mathrm{SD})$

\begin{tabular}{lccc}
\hline & $\begin{array}{c}\text { Group T } \\
(\mathbf{n}=\mathbf{2 1})\end{array}$ & $\begin{array}{c}\text { Group L } \\
(\mathbf{n = 2 1 )}\end{array}$ & $\mathbf{p}$ \\
\hline Age & $43.23 \pm 13.25$ & $48.61 \pm 9.99$ & 0.145 \\
\hline BMI & $25.82 \pm 3.73$ & $26.69 \pm 4.14$ & 0.481 \\
\hline Surgery time & $68.80 \pm 16.72$ & $58.80 \pm 8.64$ & $\mathbf{0 . 0 2 4}$ \\
\hline $\begin{array}{l}\text { Gender } \\
\text { (Male / Female) }\end{array}$ & $13 / 8$ & $11 / 10$ & 0.53 \\
\hline *statistically significant & & &
\end{tabular}

*statistically significant.
When the average tramadol consumptions per patient were compared in the first 24 hours postoperatively, they were determined as $19.04 \pm 40.23 \mathrm{mg}$ in Group T and $27.38 \pm 44.65$ $\mathrm{mg}$ in Group L. There was no statistically significant difference between the groups $(p=0.519)$ (Table III).

Postoperative analgesia times were $21.14 \pm 6.08$ hours in Group T and $21.14 \pm 4.92$ hours in Group L. There was no statistically significant difference between the groups $(p=0.686)$ (Table III).

Complication was detected in $4.8 \%(n=2)$ of the patients in Group T and 4.8\% ( $n=2)$ in Group L. There was no statistically significant difference between the groups $(p=1.00)$ (Table III). The complication recorded was hypotension in all instances and was treated with ephedrine.

VAS scores at the $1^{\text {st }}, 4^{\text {th }}$, and $8^{\text {th }}$ hours were statistically lower in Group L than those in Group T ( $p$ values: 0.011, 0.028, and 0.029). In the follow-up at other hours, similar results were detected in all groups. The mean 24-hour VAS values were 1.08 in Group T and 0.74 in Group L (Table IV).

When the groups were compared in terms of block application times, theirs were calculated as $7.38 \mathrm{~min}$ in Group T and 2.42 min in Group L. Block time was found statistically shorter in Group $L(p=0.001)$. The discharge times of the patients were $50.28 \pm 16.8$ hours in Group T and $51.42 \pm 11.47$ hours in Group L. There was no statistically significant difference between the groups $(p=0.348)$. There was no statistically

Table II: Visual Analog Scale Values and Rescue Opioid Doses

\begin{tabular}{|c|c|c|c|c|c|}
\hline Group & VAS $^{*}$ & \multicolumn{3}{|c|}{ Rescue tramadol amount } & $\begin{array}{l}\text { Total } \\
\text { n (\%) }\end{array}$ \\
\hline \multirow{3}{*}{ Group T } & $\leq 3$ (mild) & 17 & 0 & 0 & 17 (80.9) \\
\hline & 4-6 (moderate) & 0 & 4 & 0 & $4(19)$ \\
\hline & 7 to 10 (severe) & 0 & 0 & 0 & 0 \\
\hline \multirow{4}{*}{ Group L } & $\leq 3$ (mild) & 15 & 0 & 0 & $15(71.4)$ \\
\hline & 4-6 (moderate) & 0 & 6 & 0 & $6(28.5)$ \\
\hline & 7 to 10 (severe) & 0 & 0 & 0 & 0 \\
\hline & Total & & 21 & & $21(100)$ \\
\hline
\end{tabular}

*Visual analog scale.

Table III: Additional Analgesic Requirement, Opioid Consumption and Complication Rates

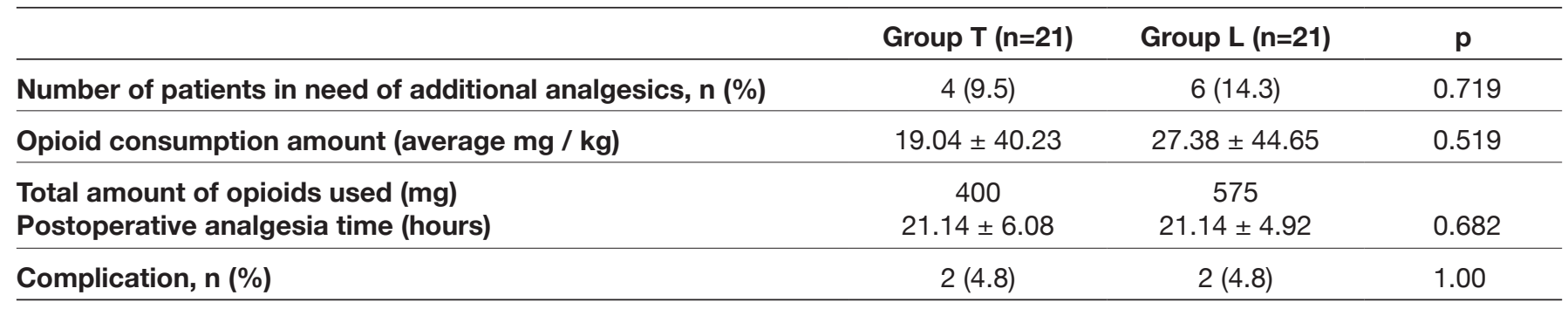


Table IV: Average Visual Analog Scale Values

\begin{tabular}{|c|c|c|c|}
\hline \multirow[b]{2}{*}{ Time } & \multicolumn{2}{|c|}{ VAS [Mean $(\min -\max )]$} & \multirow[b]{2}{*}{ p } \\
\hline & $\begin{array}{c}\text { Group T } \\
(n=21)\end{array}$ & $\begin{array}{c}\text { Group } L \\
(n=21)\end{array}$ & \\
\hline $30^{\text {th }}$ minute & $0(0-3)$ & $0(0-2)$ & 0.300 \\
\hline $1^{\text {st }}$ hour & $0(0-3)$ & $0(0-2)$ & $0.011^{*}$ \\
\hline $2^{\text {nd }}$ hour & $1(0-3)$ & $0(0-3)$ & 0.265 \\
\hline $4^{\text {th }}$ hour & $1(0-3)$ & $0(0-3)$ & $0.028^{*}$ \\
\hline $8^{\text {th }}$ hour & $1(0-4)$ & $0(0-4)$ & $0.029^{*}$ \\
\hline $12^{\text {th }}$ hour & $1(0-5)$ & $1(0-4)$ & 0.116 \\
\hline $16^{\text {th }}$ hour & $1(0-3)$ & $1(0-4)$ & 0.899 \\
\hline $24^{\text {th }}$ hour & $1(0-2)$ & $1(0-2)$ & 0.839 \\
\hline $48^{\text {th }}$ hour & $1(0-3)$ & $1(0-2)$ & 0.469 \\
\hline $72^{\text {nd }}$ hour & $1(0-3)$ & $1(0-2)$ & 0.298 \\
\hline $10^{\text {th }}$ day & $1(0-2)$ & $1(0-3)$ & 0.140 \\
\hline Average & 1.08 & 0.74 & \\
\hline
\end{tabular}

*statistically significant.

significant difference between the groups in terms of sedation and nausea scores.

\section{DISCUSSION}

In this study, performed to evaluate bilaterally modified TLIP block applied preemptively with the help of USG for the control of postoperative pain in patients scheduled for spinal surgery and local anesthetic agent infiltration to the the wound, it was concluded that the two applications did not have superiority over each other and that the duration of anesthesia was longer in the group where TLIP block was applied.

There are studies indicating that in patients who will undergo lumbar disc surgery under spinal anesthesia or general anesthesia, preemptive TLIP block application for postoperative analgesia decreases postoperative VAS scores and opioid consumption amounts more than those used in control groups and also provides an effective anesthesia for up to 24 hours when applied for this purpose $(2,16)$.

In their studies comparing saline and local anesthetic agent administration by applying bilateral TLIP block to patients scheduled for lumbar spinal surgery, Ueshima et al. concluded that the group using local anesthetic agents had lower VAS scores and opioid consumption and less nausea and vomiting and also that bilateral administration was effective (15).

In their studies to evaluate the effectiveness of local anesthetic agent, Gurbet et al. emphasized that adding adjuvants to local anesthesia did not change the pain scores and lower VAS scores and opioid consumption in all groups undergoing local anesthetics, but preemptive local anesthetic administration was more effective when they evaluated the groups in themselves (6).

Kim Sang II et al. stated that preemptive TLIP application is an effective method and can be used as a suggestion among multimodal analgesia techniques in patients with fused lumbar vertebrae (10). Therefore, we preferred to make our block applications preemptively.

Ince et al., in their study which evaluated the application of local anesthetic agent and TLIP block in patients undergoing single-level discectomy, stated that both applications had similar postoperative analgesia and VAS scores (8). The results of this study are similar to our study, but unlike Ince et al., we applied local anesthetic agent preemptively and realized our TLIP block application by using a modified technique. We recorded our VAS scores at $48^{\text {th }}$ hour, $72^{\text {nd }}$ hour, and $10^{\text {th }}$ day controls, and thus, we aimed to evaluate the effect on longterm pain. When we analyzed our results, we found that early VAS scores at the $1^{\text {st }}, 4^{\text {th }}$, and $8^{\text {th }}$ hours were lower in the locally administered group compared to those of the TLIP blockade group, but there was no statistically significant difference between the other late follow-ups and $10^{\text {th }}$ day controls.

In their study, Ince et al. stated that there was no difference in terms of surgical time between the two groups, and in our study, we found the duration of surgery longer in the TLIP block group. In addition, Ince et al. preferred general anesthesia in their studies (8), and we preferred regional anesthesia in ours because the regional anesthesia technique has become widespread in these patient groups in recent years $(9,18)$.

Chen et al. emphasized that there was no significant difference between the groups with and without TLIP block in terms of surgical time and total anesthesia time (3). In our study, when we compared patients with local anesthetic agent infiltration and TLIP block application, we found that the duration of surgery was longer in the TLIP-block-treated group. As a result, we are of the idea that TLIP block application requires more skill compared to local anesthetic agent application because of the fact that it takes time to reach the correct localization and to determine the muscles with the help of USG and that the anesthesiologist makes TLIP block less frequently in other anesthesia practices compared to other blocks.

Our results show that TLIP block application is not superior to local anesthetic agent to the wound in terms of pain scores even if it is preemptive. Even local anesthetic agent application causes lower VAS scores in the early period, and bilateral block application significantly increases the duration of surgery.

When we evaluated our study in terms of complications, we found that complication developed in $9.6 \%$ of patients. The complication observed in all instances was hypotension due to spinal anesthesia and was effectively treated with ephedrine.

Dagistan et al. found that the incidence of hypotension was $25 \%$ in patients who underwent spinal anesthesia (4). We believe that, unlike Dagistan and his friends $(22.5 \mathrm{mg}$ vs. $12.5 \mathrm{mg}$ of heavy marcain), the low rate of hypotension seen in our study is due to the fact that we used local anesthetic 
medication at lower doses, and our surgical period was shorter $(83 \pm 6.3 \mathrm{~min}$ versus $63.80 \pm 14.09 \mathrm{~min})$. In addition, we think that Dagistan et al. gave propofol infusion at $25 / 50 \mathrm{mcg} / \mathrm{kg} /$ min for sedation purposes during the surgery (16), and in this case, it may have increased the rate of hypotension.

Although the techniques used do not provide superiority over each other, lower opioid usage and VAS scores are observed in both techniques, so postoperative nausea and vomiting (PONV) are less common. The lower PONV incidence is important because it leads to increased patient satisfaction, less need for nursing services, and lower hospitalization costs and times (5).

In spinal surgery patients, we have not encountered a study comparing preemptive local anesthetic agent infiltration with TLIP block application as well as evaluating long-term VAS scores, and therefore, this study is a first and is valuable.

\section{- CONCLUSION}

As a result, our study showed that in the control of postoperative pain in patients with spinal surgery when considering the postoperative opioid consumption and VAS scores, preemptive TLIP block, and local anesthetic agent infiltration to the wound are not superior to each other. TLIP block application requires more advanced techniques and skills compared to local anesthetic application, and therefore, it causes extension of total anesthesia time. Also, because of the fact that TLIP block application area is very close to the surgery area, it may not be required by surgeons due to complications such as hematoma, bleeding, and infection, which may be seen rarely. For this reason, we suggest that local anesthetic application to the wound should be preferred for the purpose of postoperative analgesia in patients scheduled for spinal surgery. We believe that the literature should be supported by a prospective study with a larger number of patients.

\section{ACKNOWLEDGMENTS}

Each author contributed equally to the development of this manuscript.

\section{- REFERENCES}

1. Ahiskalioglu A, Alici HA, Selvitopi K, Yayik AM: Ultrasonography-guided modified thoracolumbar interfascial plane block: A new approach. Can J Anesth 64(7):775-776, 2017

2. Ammar MA, Taeimah M: Evaluation of thoracolumbar interfascial plane block for postoperative analgesia after herniated lumbar disc surgery: A randomized clinical trial. Saudi J Anaesth 12(4):559-564, 2018

3. Chen K, Wang L, Ning M, Dou L, Li W, Li Y: Evaluation of ultrasound-guided lateral thoracolumbar interfascial plane block for postoperative analgesia in lumbar spine fusion surgery: A prospective, randomized, and controlled clinical trial. PeerJ 7:e7967, 2019
4. Dagistan Y, Okmen K, Dagistan E, Guler A, Ozkan N: Lumbar microdiscectomy under spinal and general anesthesia: A comparative study. Turk Neurosurg 25(5):685-689, 2015

5. Gan TJ, Meyer T, Apfel CC: Consensus guidelines for managing postoperative nausea and vomiting. Anesth Analg 97(1):62-71, 2003

6. Gurbet A, Bekar A, Bilgin H, Korfali G, Yilmazlar S, Tercan $M$ : Pre-emptive infiltration of levobupivacaine is superior to at-closure administration in lumbar laminectomy patients. Eur Spine J 17(9):1237-1241, 2008

7. Hand WR, Taylor JM, Harvey NR: Le bloc du plan interfascial thoraco-lombaire (TLIP): Une étude pilote auprès de volontaires. Can J Anesth 62(11):1196-1200, 2015

8. Ince I, Atalay C, Ozmen O: Comparison of ultrasoundguided thoracolumbar interfascial plane block versus wound infiltration for postoperative analgesia after single-level discectomy. J Clin Anesth 56:113-114, 2019

9. Jellish WS, Thalji Z, Stevenson K, Shea J: A prospective randomized study comparing short-and intermediate-term perioperative outcome variables after spinal or general anesthesia for lumbar disk and laminectomy surgery. Anesthesia \& Analgesia 83(3):559-564, 1996

10. Kim S-II, Ha KY, Oh IS: Preemptive multimodal analgesia for postoperative pain management after lumbar fusion surgery: a randomized controlled trial. Eur Spine J 25(5):16141619, 2016

11. Mullen JB, Cook WA: Reduction of postoperative lumbar hemilaminectomy pain with Marcaine. Technical note. J Neurosurgm 51(1):126-127, 1979

12. Ozyilmaz K, Ayoglu H, Okyay RD: Postoperative analgesic effects of wound infiltration with tramadol and levobupivacaine in lumbar disk surgeries. J Neurosurg Anesthesiol 24(4):331335, 2012

13. Prabhakar H, Ali Z: Textbook of Neuroanesthesia and Neurocritical Care, Vol I. Springer Singapore, 2019

14. Swennen C, Bredin S, Eap C, Mensa C, Ohl X, Girard $V$ : Local infiltration analgesia with ropivacaine in acute fracture of thoracolumbar junction surgery. Orthop Traumatol Surg Res 103(2):291-294, 2017

15. Ueshima $H$, Hara E, Otake $H$ : Thoracolumbar interfascial plane block provides effective perioperative pain relief for patients undergoing lumbar spinal surgery; a prospective, randomized and double blinded trial. J Clin Anesth 58:12-17, 2019

16. Ueshima H, Ozawa $\mathrm{T}$, Toyone $\mathrm{T}$, Otake $\mathrm{H}$ : Efficacy of the thoracolumbar interfascial plane block for lumbar laminoplasty: A retrospective study. Asian Spine J 11(5):722725, 2017

17. Wheeler M, Oderda GM, Ashburn MA, Lipman AG: Adverse events associated with postoperative opioid analgesia: $A$ systematic review. J Pain 3(3):159-180, 2002

18. Zorrilla-Vaca A, Healy RJ, Mirski MA: A comparison of regional versus general anesthesia for lumbar spine surgery: $A$ meta-analysis of randomized studies. J Neurosurg Anesthesiol 29(4):415-425, 2017 